


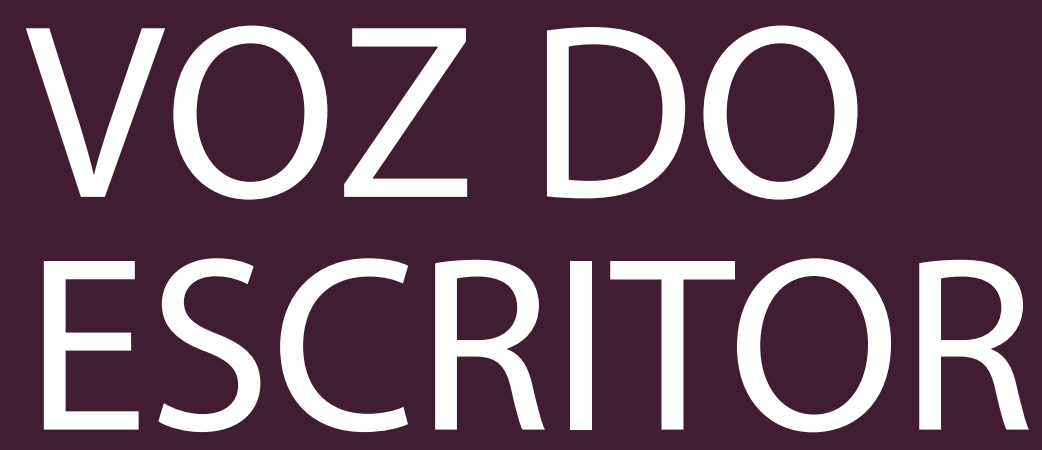




\title{
QUATRO POEMAS DE MARÍLIA GARCIA
}

- MARÍLIA GARCIA

\section{ESTRELAS DESCEM À TERRA}

\author{
começo do começo, \\ que foi quando me pediram \\ os poemas que leria no encontro \\ "a voz do escritor": \\ ainda faltava 1 mês \\ para este encontro \\ e eu não tinha ideia do que aconteceria \\ entre o dia do convite e o dia \\ de estar aqui hoje \\ assim, \\ esta voz que fala aqui \\ é a voz de uma marília de um mês atrás \\ é a minha voz falando a partir do passado, \\ é a minha voz, \\ mas sem controle.
}

há um mês eu não tinha

como prever o que aconteceria

e eu pensei que se este mês

seguisse o ritmo acelerado

e catastrófico do último ano

tanta coisa já teria 
acontecido hoje,

que me dava medo

imaginar.

e eu fiquei me

perguntando:

— com quem estou falando aqui hoje?

e eu fiquei me perguntando:

- como fazer para essas palavras escritas

no passado dizerem algo

sobre estar aqui

agora?

e eu não soube responder.

então, fiquei me perguntando

se hoje faria frio ou não,

e se haveria poeira no ar.

eu sempre me surpreendo

com a poeira que turva a vista:

de repente no meio do dia

uma poeira que se ergue,

uma nuvem

de poeira,

pode ser a poeira vinda das coisas quebradas

todos os dias na vida das pessoas

e eu pensei que talvez a gente pudesse

fazer silêncio

e deixar a escuta aberta

para ouvir.

talvez a gente pudesse fazer silêncio

e de repente neste silêncio

acontecer de ouvir algo por detrás

dos ruídos das máquinas que

cruzam o céu.

talvez não desse para ouvir as máquinas voadoras

neste dia,

foi o que pensei,

mas eu me enganei

porque hoje

desde cedo 
os helicópteros estão voando.

— vocês estão ouvindo?

um som infernal

estrelas caindo do céu

em cima da cabeça

o som está cada vez mais perto,

posso encostar a mão

se me viro vejo a sombra

em câmera lenta

sobre a cabeça.

imaginem que isso aqui é um quadrado

com drones volantes,

ou uma cena congelada

com o céu cheio de zepelins,

mas o som é um só:

barulho de máquinas

voadoras

pelo céu.

se a gente prestar atenção e fizer silêncio

— se a gente prestar atenção e fizer

silêncio -

pode ser que ouça

alguma mensagem

perdida no ar.

(versão do poema “hola, spleen", do livro Câmera lenta, 2017)

\title{
UMA EQUAÇÃO NO HYDE PARK
}

\author{
está chovendo no \\ hyde park hoje \\ e estou do outro \\ lado do hemisfério \\ sentada ao sol \\ com um gato \\ entre meus pés \\ que estão descalços
}




\author{
e levemente \\ avermelhados. \\ está chovendo no \\ hyde park hoje \\ e lembro de ter \\ andado num parque \\ de ângulos quadrados \\ com o menino da caixa \\ preta que tinha uma foto \\ de uma floresta nórdica \\ virada de ponta-cabeça na \\ parede do seu quarto \\ e que gostava de contar \\ até 24 depois de cruzar \\ o gradil.
}

a gente andava

no meio-fio e sentava

no parque e depois deitava e o

roupão preto felpudo

já na casa dele

e o roommate chamado

steve que amava

uma japonesa.

está chovendo no

hyde park hoje e não sei

o que dizer a ele

que agora está sentado

algumas mesas à frente

e que dentro de um filme

seria alguém que diz sim

mas não estou dentro de um

filme - ouço a voz em eco

no buraco do real -

e me refaço pensando

que podia contar

que o gps funcionou

e indicou o ponto de encontro

mas a mensagem 
só chegou depois.

está chovendo no

hyde park hoje

e podia contar que meu

coração tinha sido arrancado

pela boca e que estava

esquecido sobre uma pedra

com o sangue

ainda quente.

sim, está chovendo

no hyde park

e ao inferno

já desceram

um ou dois

ou

três

mas ele

há de subir

atravessando as curvas,

o belvedere, os espaços dirigíveis

"ogni speranza lasciate

voi che entrate"

- há mundo por vir?

ele pergunta antes de passar

e leva na mão

um gravador

e nós cruzamos o olhar

— só por um segundo -

e não lembro mais

desse dia

mas depois o

mesmo olhar

volta à memória

como a interferência

de uma voz saindo

do carro em movimento

pela ladeira. 
está chovendo no

hyde park e aquele par

de olhos encontra os meus,

e esse cruzamento

de olhares me distrai

por um momento

da equação.

(do livro Câmera lenta, 2017)

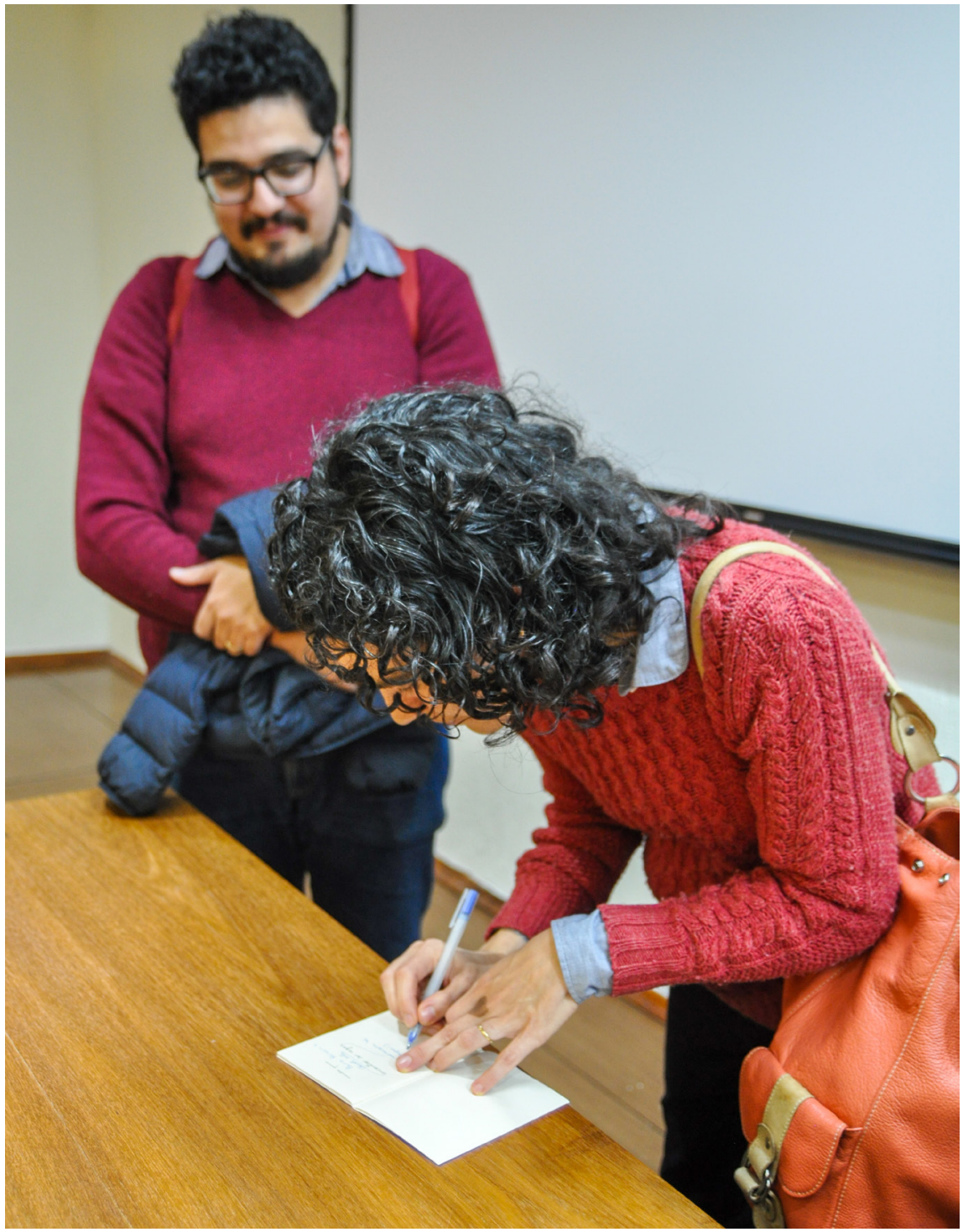




\section{É UMA LOVE STORYE É SOBRE UM ACIDENTE}

primeiro, a cena congelada.

um dedo pousa no vidro,

a tela vibra.

você lembra o que

disse na hora? você gritou? doeu?

você lembra do que aconteceu?

- a curva, a chuva, um clarão.

você lembra o que disse na hora

em que o carro deslizou?

três horas na chuva esperando,

a curva, o estrondo - você lembra?

você entre as ferragens

perguntando o que houve.

(mas isso é um acidente

e é sobre uma love story)

o amor, diz, é um efeito especial,

pensa que viu tudo

mas quando acende a luz

os pontos

cegos se espalham:

uma fossa abissal, uma nuvem

de distância e uma cidade chamada vidro ou

vértice

volpi ou verdi.

o amor é alguém entrando

na geometria da sua mão.

neste momento atravessa o corredor:

- não há mais isso entre nós,

de onde o timbre da sua voz

um efeito-estertor.

o amor é isso, diz, não um corvo,

mas um impermeável vermelho pendurado

na janela vindo de outro poema

para tocar na sua tela. 
é você comendo o que sobrou

depois do estrondo.

"é difícil olhar as coisas

diretamente",

elas são muito luminosas

ou muito escuras

2/3 deste país são feitos de água

e sempre que se vira, um

afogamento.

apenas um mergulho

dizia a imagem. vamos ver o deserto,

andar pelo centro do mundo?

mas isso é um dicionário

e é sobre uma love story.

(do livro Câmera lenta, 2017)

\title{
ORDEM ALFABÉTICA
}

\author{
já falei em algum canto \\ sobre este poema \\ ["a garota de belfast ordena a teus pés \\ alfabeticamente"] \\ então começo de novo \\ queria contar como foi o começo \\ beginning again \\ contar como comecei a escrever \\ este poema \\ peguei o livro a teus pés \\ e reordenei os versos \\ em ordem alfabética \\ depois peguei uma personagem do joseph brodsky \\ que estava em belfast \\ dangerous town ele diz \\ ela tinha os cabelos curtinhos
}


para que menos partes suas sofressem

quando alguém a machucasse

a garota de belfast fez o poema

recortando os versos de ana c. que começavam

com a letra $a$

hoje é dia 18 de dezembro de 2013

e estamos imersos em listas e mais listas

que seguem enumerando os acontecimentos do ano

os maiores feitos e os melhores

isso foi o que eu disse para ela

mais cedo quando o telefone tocou

e estávamos as duas soterradas em tantas

listas

o som ao redor é um grande filme

ela disse e eu concordei

mas não queria saber de listas

eu disse e pensei que hoje

é dia 18 de dezembro de 2013

e estou mais para outro tipo de enumeração

em ordem alfabética

escolha um livro de que você goste

e ordene alfabeticamente

a garota de belfast ordena a teus pés alfabeticamente

98 voltas pelo parque antes de cair em

círculos sobre o próprio peso

98 vezes dizia o mesmo:

você pode ou não pensar em algo

definitivo. parecia a garota de belfast com

sua memória dobrada como um paraquedas

dentro do tecido eletrizado.

enquanto falava descia a

escada lateral recortando os ruídos

da orquestra. a roda da bicicleta

girando em loop esfarelando os

reflexos no ar e seis horas parada diante

do ralo, pode ou não pensar em algo, sentada na beira do

quarto. olha de longe quando o carro

passa, desce à noite pelos trilhos

quando tudo é uma vingança 
fala de pontes atravessando os túneis da cidade e ordena a teus pés alfabeticamente
a anoitecer sobre a cidade
a câmera em rasante
a correspondência
a curriola consolava
a dor
a espera
a intimidade era teatro
...
a tomar chá, quase na borda
a voz em off nas montanhas
abre a boca, deusa
abria a cortina
acho que é mentira

pode ou não pensar que era sua voz em mountain hill a uma velocidade de $1 \mathrm{~km} / \mathrm{h}$ ou mil. antes

de voltar para a irlanda já começara a perder. entende que só depois de o blindex esfarinhado contra a cabeça, só em poucos segundos até que a cabeça contra o blindex, mas era apenas parte do trajeto, não tinha como calcular as noites ou linhas em que passaria.

"como extrair o áudio de uma imagem congelada" era a etiqueta que colava nas paredes para tentar descobrir como chegar com precisão e ao fundo a voz pela fresta a ordenar este livro:

agora nessa contramão

agora chega

agora é a sua vez

agora estamos em movimento

agora pouco sentimental

agora sou profissional

água 


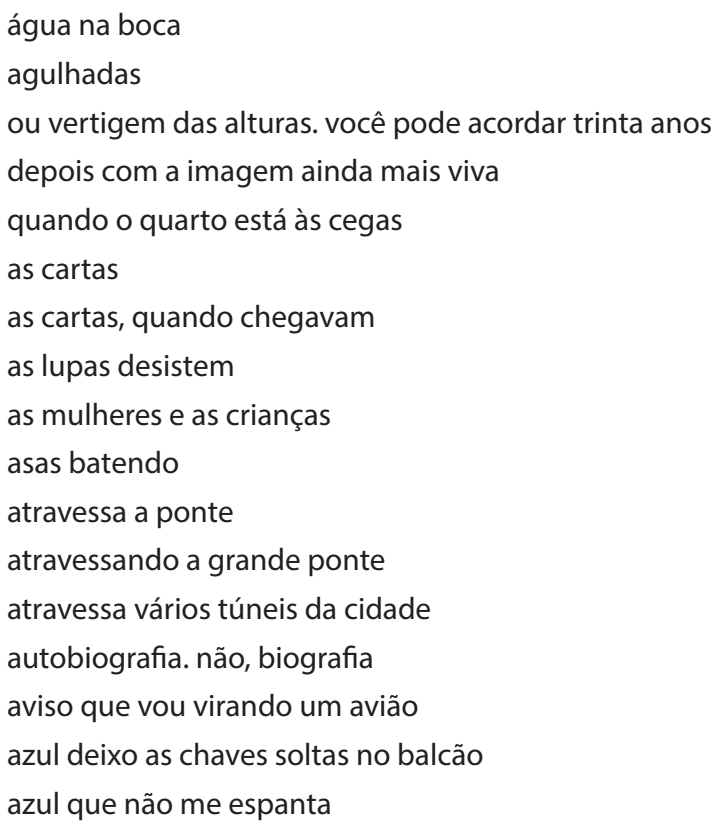

(do livro Um teste de resistores, 2014)

MARÍLIA GARCIA - Formada em Letras e doutora em Literatura Comparada, é poeta, tradutora e editora brasileira. Publicou os livros 20 poemas para o seu walkman (Cosac Naify, 2007), Engano geográfico (7Letras, 2012), Um teste de resistores (7letras, 2014), Paris não tem centro (7letras, 2015), e Câmera lenta (Companhia das Letras, 2017). 